\title{
Changing Trends in the Labor Force: A Survey
}

\author{
Riccardo DiCecio, Kristie M. Engemann, Michael T. Owyang, and Christopher H. Wheeler
}

\begin{abstract}
The composition of the American workforce has changed dramatically over the past half century as a result of both the emergence of married women as a substantial component of the labor force and an increase in the number of minority workers. The aging of the population has contributed to this change as well. In this paper, the authors review the evidence of changing labor force participation rates, estimate the trends in labor force participation over the past 50 years, and find that aggregate participation has stabilized after a period of persistent increases. Moreover, they examine the disparate labor force participation experiences of different demographic groups. Finally, they survey some of the studies that have provided explanations for these differences. (JEL J21, E32)
\end{abstract}

Federal Reserve Bank of St. Louis Review, January/February 2008, 90(1), pp. 47-62.

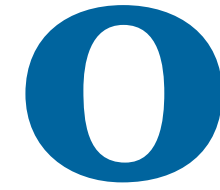

ne of the primary indicators of the state of the U.S. labor market is the labor force participation rate (LFPR). It is measured each month by the Bureau of Labor Statistics (BLS) as the fraction of the civilian, non-institutional population 16 years or older who are either working or actively seeking work. The LFPR is a useful complement to other indicators, such as employment and the unemployment rate, in assessing labor market conditions. For example, a low unemployment rate is a much stronger indication of a tight labor market when accompanied by a high participation rate.

Although the LFPR is constantly changing over the business cycle, the most noticeable feature is its dramatic increase over the post-World War II period. Between 1948 and 2006, the U.S. LFPR rose by more than 7 percentage points, with the majority of the rise taking place between the early 1960s and 2000. This increase implies that, compared with several decades ago, there are more individuals currently participating in the labor market relative to the total number of residents in the country. Such a trend has likely contributed to the rise in U.S. living standards (e.g., income per capita) over the postwar period. In spite of this long-run rise in the LFPR, there has been a modest drop in the overall participation rate within the past six years, which has generated some concern among economists. If this decrease represents a change in the trend LFPR, the U.S. economy may be faced with fewer work-oriented individuals per resident in the coming decades.

What accounts for the changes in the LFPR in the United States over the past several decades? Numerous studies have documented changes in various U.S. demographics, including the age and ethnic composition of the population, that have significantly affected the nature of the labor force. In 1960, prime-age white males-from 25 to 54 years of age-comprised, by far, the largest labor force component: nearly 40 percent. Although this group still represented 31 percent of the work-

Riccardo DiCecio is an economist, Kristie M. Engemann is a senior research associate, Michael T. Owyang is a research officer, and Christopher H. Wheeler is a research officer at the Federal Reserve Bank of St. Louis. The authors benefited from conversations with Alessandra Fogli, Leora Friedberg, and Natalia Kolesnikova.

(C) 2008, The Federal Reserve Bank of St. Louis. Articles may be reprinted, reproduced, published, distributed, displayed, and transmitted in their entirety if copyright notice, author name(s), and full citation are included. Abstracts, synopses, and other derivative works may be made only with prior written permission of the Federal Reserve Bank of St. Louis. 


\section{Figure 1}

\section{Labor Force Participation Rate}
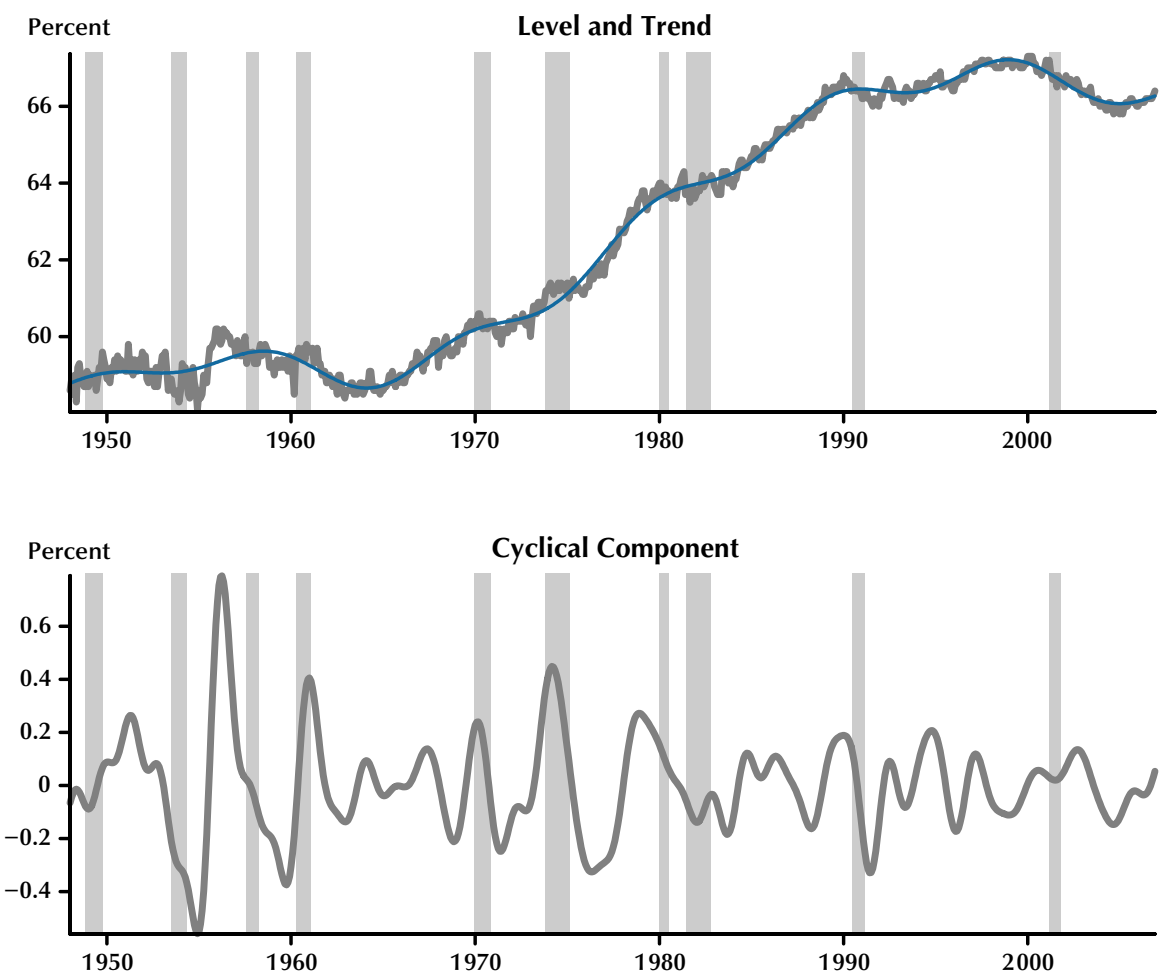

NOTE: Top panel: level (gray) and trend (blue) extracted with an $\mathrm{LP}_{96}$ filter. Bottom panel: cyclical component extracted with $\mathrm{BP}_{18,96}$ filters. The shaded areas denote National Bureau of Economic Research (NBER) recessions.

force in 2005, the gap with other demographic groups appears to be closing. In particular, increases in both minority and women workers have dramatically altered the composition of the workforce. Moreover, the aging of the baby boomers has changed the age profile of the American population.

In this paper, we review the trends in labor force participation over the past half century, including a look at both the long-run movements in the LFPR as well as its short-run fluctuations. We then examine the components of the LFPRdisaggregating by gender, age, and race- - to determine the extent of and possible explanations for the dispersion in labor force participation across demographic groups. Finally, we consider the future of the LFPR in the United States.

\section{TRENDS IN AGGREGATE LABOR FORCE PARTICIPATION}

The BLS maintains a monthly history of labor force participation statistics dating back to 1948. These figures are derived from the Current Population Survey, which reports information on approximately 60,000 households. ${ }^{1}$ The top panel of Figure 1 shows the historical path of aggregate labor force participation in the United States; the overall increase in the participation rate since 1948 is evident. In January 1948, the overall rate of labor force participation in the United States was roughly 59 percent. This rate held fairly steady until the early 1960s, when it

\footnotetext{
1 Unless otherwise noted, the source for data used in the figures is the BLS.
} 
began to rise; during the first quarter of 2000 , the LFPR achieved its highest level-67.3 percent of the working-age population. Over the past few years, however, the LFPR fell from its 2000 level to 65.8 percent in January 2005. It has since rebounded to 66.4 percent as recently as December 2006.

Although the LFPR unquestionably trended upward over the latter half of the twentieth century, the nature of its recent decline has sparked some debate. Some economists argue that the decrease reflects structural changes in the labor market (i.e., a change in the trend of the LFPR), whereas others view it primarily as a cyclical deviation from the trend. Aaronson et al. (2006), for example, use a cohort-based model to show that the decline from 2000 until 2002 occurred as a result of the weak labor market conditions stemming from the 2001 recession. Although the initial drop in the LFPR was due to cyclical factors, their estimates indicate that the trend LFPR began to decline in 2003. On the other hand, Bradbury (2005) argues that the decline since 2001 is a reflection of slack in the economy and is purely cyclical, although she does note that, relative to previous economic recoveries, the period following the 2001 recession was characterized by unusually low participation rates among teenagers and women.

To gauge the degree of labor market tightness, it is important to determine how changes in the trend and in the cyclical component contribute to movements in the LFPR. If structural factors cause most of the decline in participation, then a low unemployment rate indicates a tight labor market. On the other hand, if business cycle movements cause most of the decline, a substantial part of it should be reversed in a relatively short period of time. People who temporarily dropped out of the labor force will start looking for jobs again and thus will be recorded as unemployed. In the latter case, a low unemployment rate overstates labor market tightness.

A cursory examination of Figure 1 suggests that there may have been at least three different regimes describing the LFPR over the past six decades: zero growth before 1960, a constant trend growth between 1960 and 2000, and a declining trend subsequent to the turn of the century. To estimate more formally how the trend in the LFPR has evolved over time, we follow a standard technique in which we use a low-pass filter to remove high-frequency fluctuations from the raw data. ${ }^{2}$ In particular, we remove cycles with a period less than 96 months. The resulting trend is shown in the top panel of Figure 1. Consistent with the business cycle tradition, we then identify the business cycle component of the LFPR data with cycles of periods between 1.5 and 8 yearsi.e., 18 and 96 months-which we extract by applying a band-pass filter. ${ }^{3}$ The bottom panel of Figure 1 shows the business cycle components of the LFPR. ${ }^{4}$

Based on these calculations, we find that the trend component peaked in October 1998 at 67.2 percent, declined afterward to a minimum of 66.1 percent in January 2005, and increased by 0.2 percentage points by the end of $2006 .{ }^{5}$ The cyclical component of the LFPR increased slightly after the 2001 recession, declined until August 2004, and recovered afterward.

To demonstrate some of the short-run cyclical properties of the LFPR series, we compare the business cycle component of the LFPR with those of a common indicator of aggregate activity, industrial production. ${ }^{6}$ The correlation between the two and their relative standard deviations are reported in Table 1. Based on the correlation, we see that the LFPR is moderately procyclical (i.e., it rises during expansions and falls during contractions). This finding is consistent with the idea that during economic upturns, potential workers are lured into the labor force because they perceive their job prospects to be strong. During recessions, on the other hand, workers not only

2 For an overview of terminology, see the appendix

3 See Baxter and King (1999) and Christiano and Fitzgerald (2003).

4 To consider the decline in the LFPR from early 2000 to the end of 2005 and its slight recovery afterward as purely cyclical phenomena, fluctuations with a period of up to 36 years would need to be removed in the definition of the trend.

5 Clark and Nakata (2006) estimate the trend growth rate in the LFPR to be 0.3 percent from 1957-81 and 0.2 percent from 19812005. They attribute the decline in the trend to the deceleration of women's LFPR.

6 Industrial production data come from the Federal Reserve Board. 
Table 1

Second Moments of the Business Cycle Components of LFPR, Total and by Gender

\begin{tabular}{lccc} 
& Total & Men & Women \\
\hline $\operatorname{Corr}(x, i p)$ & 0.35 & 0.41 & 0.28 \\
& $(0.13,0.53)$ & $(0.24,0.56)$ & $(0.04,0.46)$ \\
$\operatorname{Std}(x) / \operatorname{Std}(i p)$ & 0.09 & 0.07 & 0.19 \\
& $(0.07,0.11)$ & $(0.05,0.08)$ & $(0.14,0.24)$
\end{tabular}

NOTE: ip denotes industrial production. Block-bootstrapped 95 percent confidence intervals are in parentheses.

lose jobs-thereby increasing unemploymentbut also exit the labor force altogether because the number of employment opportunities becomes relatively scarce.

These fluctuations in the LFPR, however, are small compared with those in industrial production. Indeed, we find that the LFPR is one-tenth as volatile as industrial production at business cycle frequencies. This property of the LFPR may reflect a high degree of inflexibility in the average individual's labor force participation decision over time. Because individuals need an income to support their consumption, many decide to work (or at least seek work) regardless of whether the economy is expanding or contracting.

The vast majority of the movement of the LFPR, however, is associated with its trend, not its cyclical components. In the next sections, we explore the long-run evolution of the LFPR by looking at its disaggregate components-specifically, its gender, age, and racial components.

\section{GENDER AND THE LFPR}

A substantial portion of the rise in the aggregate LFPR beginning in the 1960s can be attributed to the rise in the labor force participation of women. In 1950, approximately one in three women 16 years of age or older participated in the labor force. Figure 2 illustrates the rise in female labor force participation over the latter half of the twentieth century: The LFPR for all women is depicted by the solid blue line, while the solid black and dotted lines show the LFPR for married and single women, respectively. ${ }^{7} \mathrm{By}$ 1999, the overall female LFPR rose to its peak of 60 percent. As Figure 2 shows, much of the increase in women's participation can be attributed to married women, whose LFPR rose by more than 30 percentage points between 1955 and 2005. The LFPR of single women has also increased over the past several decades, but much more modestly. Since 1999, the overall women's LFPR has remained fairly steady: between 59 and 60 percent.

Figure 3 highlights the differences in the LFPR across genders. In particular, Figure 3 reveals a persistent decline in men's LFPR since 1950, the same period over which women's LFPR saw its most significant increase. During that period, the male LFPR fell by 13 percentage points to its 2006 rate of less than 75 percent.

The cycle decomposition of the LFPR by gender bears some similarity to that of the aggregate (Table 1); however, two important differences emerge. First, men's participation tends to be somewhat more procyclical than women's participation. The correlation between industrial production and men's LFPR at business cycle frequencies is 0.41 , whereas the same correlation for women's LFPR is 0.28 . This result may, in part, reflect the added-worker effect, in which women enter the labor force to compensate for a spouse's loss of a job. That is, as men become unemployed during an economic downturn, some women may choose to enter the labor force to off-

\footnotetext{
7 A fourth category, not shown in the figure, includes widowed, divorced, and separated women. Their LFPR held fairly steady around 40 percent between the mid-1950s and the mid-1970s and increased by less than 10 percentage points by the early 2000 s.
} 


\section{Figure 2}

\section{LFPR by Marital Status (Women)}

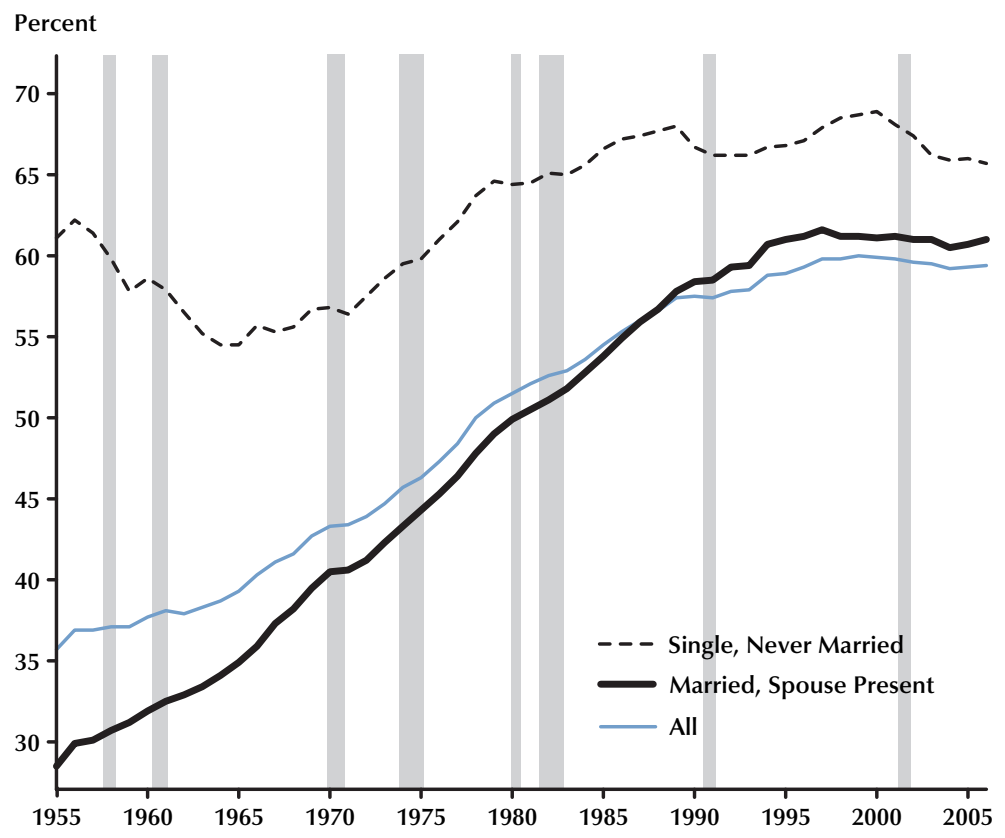

NOTE: The data used in this figure are unadjusted annual percentages. The shaded areas denote NBER recessions.

SOURCE: 1955-75, U.S. Census Bureau, Statistical Abstract of the United States, 2003, www.census.gov/statab/hist/HS-30.pdf; 1976-2005, Bureau of Labor Statistics.

set the loss in household income. This phenomenon may temper the procyclicality of the female participation rate somewhat. Second, the LFPR for women is nearly three times more volatile than the LFPR for men, which may reflect the idea that society has viewed women as the primary child-rearer and the secondary earner. ${ }^{8}$ Thus, while these days more women may be working at any given time, they may remain more likely than men to move in and out of the labor force.

The dramatic increase in married women's labor force participation has been the subject of

8 Compared with the first part of the sample, the volatilities of the business cycle components were 1.5 and 3 times smaller for men and women, respectively, after 1984. Stock and Watson (2003) demonstrate the decline in volatility of many macroeconomic variables, but they do not consider the labor force. However, they do show that the conditional variance for civilian employment has declined since the mid-1980s (or since the mid-1970s when a trend is included). many studies, too numerous to detail here. We highlight only a few of the myriad possible explanations. The improvement in labor-saving household technologies has simplified many daily tasks, such as cooking and cleaning, thereby giving women greater time to pursue work outside of the home (Greenwood, Seshadri, and Yorukoglu, 2005). This hypothesis is supported by evidence on the differences in married women's labor force participation decisions across cities. In a recent study, Black, Kolesnikova, and Taylor (2007) find that married women's LFPR was substantially lower in cities with more traffic congestion, proxied by longer average commuting time. Controlling for other factors such as the woman's age, education, non-labor income, number of children by age group, and MSA unemployment rate among white men, a small increase in a city's average commuting time significantly reduced married 


\section{Figure 3}

\section{LFPR by Gender}
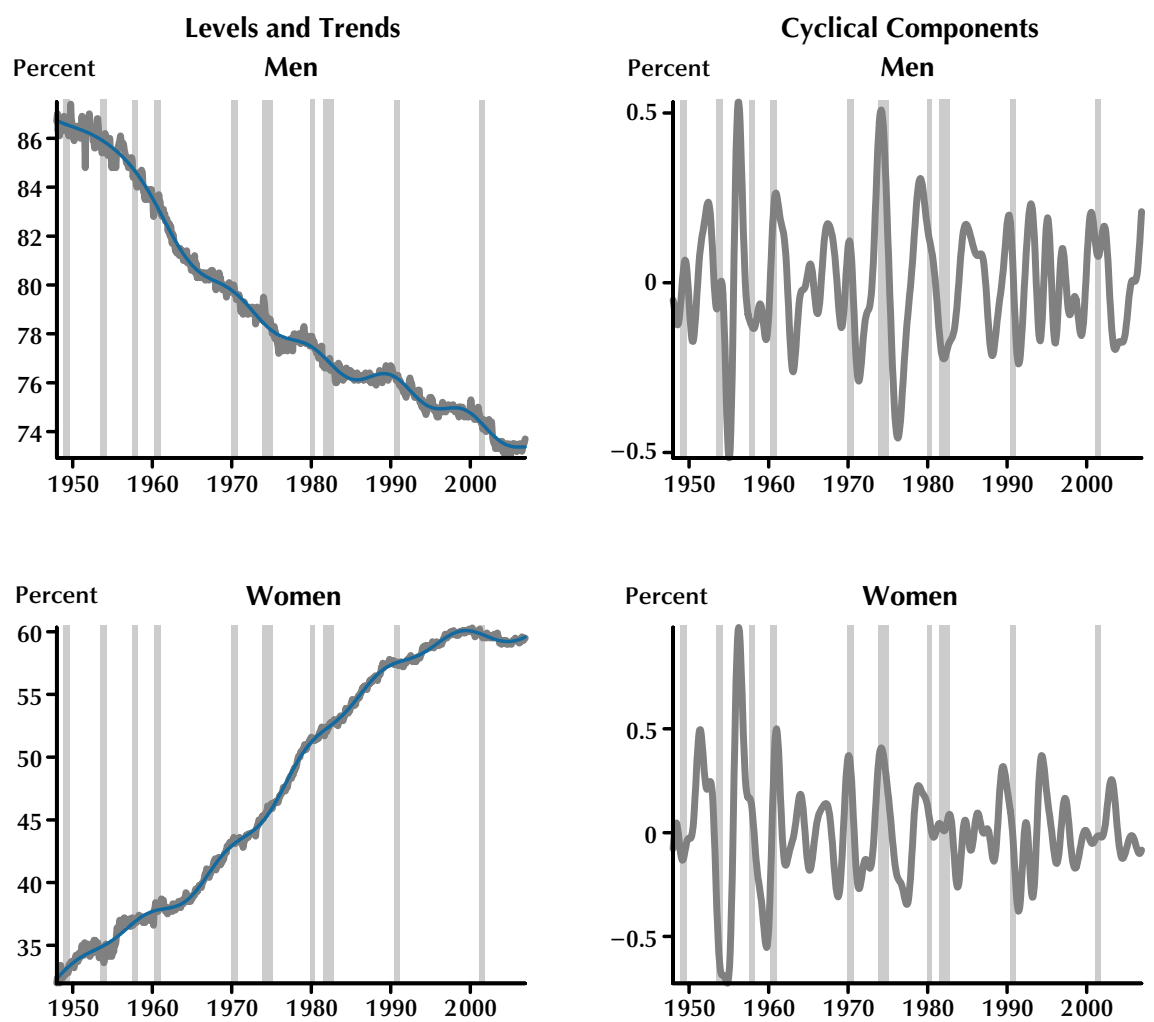

NOTE: Left column: levels (gray) and trends (blue) extracted with an $\mathrm{LP}_{96}$ filter. Right column: cyclical components extracted with $\mathrm{BP}_{18,96}$ filters. The shaded areas denote NBER recessions.

women's labor force participation. ${ }^{9}$ If cities with greater congestion involve greater amounts of time required to run errands (part of household production), women might participate in the labor force less in those cities.

Alternatively, medical advances, such as the birth control pill, have allowed women to delay marriage and pregnancy, thus providing more opportunity to invest in a career early in life (Goldin and Katz, 2002). Changes in societal attitudes have also made it more acceptable for

9 For women with children under the age of 5, the effects were largest. In particular, an increase of one minute in the average MSA commuting time led to a 0.53-percentage-point decrease in the LFPR of women with a high school education. For women with a college education, their LFPR decreased by 0.22 percentage points. married women and women with young children (under the age of 6) to work (Aaronson et al., 2006). Fernández, Fogli, and Olivetti (2004) find that men whose mothers worked when they were young children seemingly had a preference for wives who also worked. These social changes have enabled more women to pursue careers in professional fields such as business, law, and medicine, which has in turn led to higher returns to experience, both in absolute terms and relative to those of men (Goldin, 2006).

Fogli and Veldkamp (2007) consider that "learning" is the underlying force behind the sharp rise in participation rates for married women with young children. When deciding whether to join the labor force, women try to understand 
how important stay-at-home child rearing is in determining the future labor market outcomes of their offspring; stated another way, they observe the outcomes of children of working women to assess the importance of nature versus nurture. As more women join the labor force, learning happens at a faster pace, which reinforces the increase in participation and generates the Sshaped participation rate observed in the data. Fogli and Veldkamp's model is consistent with survey data that indicate an increasing positive attitude toward mothers who participate in the labor force. The model is also consistent with the continuous increase in women's wages over the past two decades, despite a flattening participation rate. In a related paper, Fogli, Marcassa, and Veldkamp (2007) argue that the rise in women's LFPR over the second half of the previous century can be partly explained by a spatial component. In other words, a county whose neighbors have high female LFPRs is likely to also have a high female LFPR. This is because, over time, learning occurs and cultural effectsincluding women's increased participation in the labor force-spread to nearby counties.

Figure 2 shows that the increase in women's LFPR began to slow in the 1990s. Blau and Kahn (2007) argue that the responsiveness of women's labor supply to changes in their wages decreased by about half between 1980 and 2000. Moreover, changes in their husbands' wages had less of an impact on married women's labor supply during this period. One explanation that the authors provide is that, as more women entered the labor force, they became more attached to working and thus less responsive to changes in wages. Also, higher rates of labor force participation meant that fewer women were on the margin, taking a wait-and-see approach to entering the labor force. The end result was slower growth of women's LFPR during the previous decade. ${ }^{10}$

As with the rise in women's LFPR, many factors have likely caused the decline in men's LFPR. Hotchkiss (2005) cites several reasons that have

\footnotetext{
${ }^{10}$ Cohany and Sok (2007) discuss changes in the LFPR of married women with children of various ages. They show that of all married mothers, those with infants have experienced the largest decline in their LFPR since the late 1990s.
}

led to earlier retirement, such as the creation of Social Security in 1935 and firms' increased provision of private pensions following the Revenue Act of 1942. She also notes that the expansion of Social Security to include disability insurance gave workers more incentive to leave the labor force due to disability. Juhn (1992) argues that the decline in real wages of less-skilled workers between 1967 and 1987 caused most of the decline in employment of prime-age men over the sample's last 15 years. Similarly, Welch (1997) finds that a shift in labor supply caused the LFPR of prime-age men to decrease in the late 1960s and early 1970s, but the decline in the subsequent two decades was caused by a change in relative wages (i.e., lower wages for less-educated compared with college-educated men). One might think that the rise in women's participation rates would be a contributing factor to the decline in men's participation rates; primarily, if a husband has a working wife, he has less incentive to be in the labor force. However, Juhn and Murphy (1997) show that the evidence does not support this claim. Despite an increase in employment among wives of low-wage men between 1969 and 1989, the change was much less than the increase in employment among wives of middle- and highwage men.

\section{AGE AND THE LFPR}

One of the most important demographic changes affecting the U.S. LFPR is the evolution of the population's age distribution. Most noticeably, the approximately 78 million individuals belonging to the baby-boom generation-those born between 1946 and 1964-have been reaching the latter stages of their working lives. With such a large fraction of the U.S. population growing older, the recent decline in the overall LFPR is understandable.

To get a sense of the influence the boomers have exerted on the LFPR, consider first the change in the median age of the U.S. labor force. As the baby-boom cohort (representing roughly one-third of the potential workforce) has grown older, the median age of the U.S. labor force has 


\section{Figure 4}

\section{Median Age of the Labor Force}

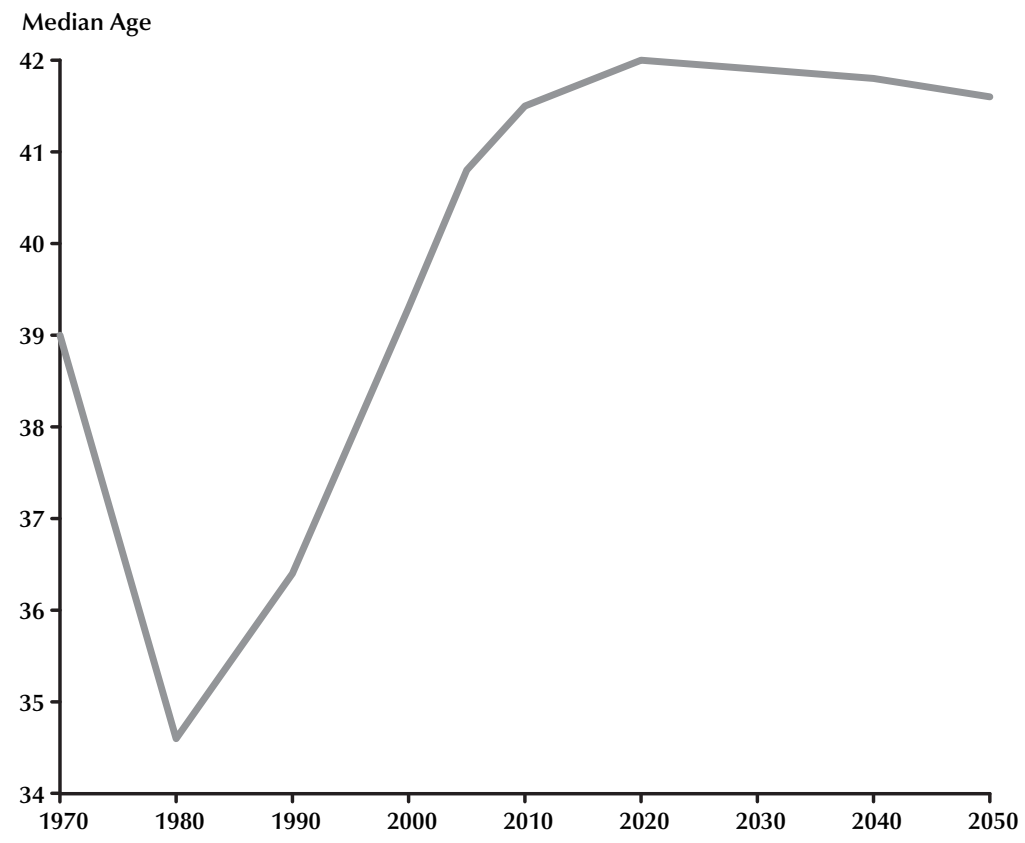

NOTE: The 1970 and 1980 data were obtained from Toossi (2002), and the remaining data were obtained from Toossi (2006).

risen from less than 35 in 1980 to almost 41 in 2005. As demonstrated by Figure 4, which shows how the median age of the labor force has changed across decades going back to 1970 as well as projections through 2050, the aging of the labor force is expected to continue at least until 2020.

The importance of the baby-boom generation in explaining the recent trends in the LFPR can be inferred from Figure 5, which highlights the differences in labor force participation across age groups. In 2000, the baby boomers were 36 to 54 years old, putting them in the prime-age working group. Not surprisingly, this group had relatively high participation rates that year: 91.6 percent of men and 76.7 percent of women had or actively sought employment (Toossi, 2005). However, after 2000 , baby boomers began moving into age categories with typically lower LFPRs. In 2005, the age group 55 to 59 was composed entirely of baby boomers, and only 78 percent of these men and 66 percent of these women were in the labor force.
Aaronson et al. (2006) estimate that about 95 percent of the total decline in the LFPR between 1995 and 2005-which was 0.44 percentage points - can be attributed to changing population shares of the different age groups. The decline in the population shares of those aged 25 to 34 and 35 to 44 caused the LFPR to decrease by 0.57 and 0.35 percentage points, respectively. The increase in the share of those aged 45 to 54 , which was made up entirely of baby boomers, caused a rise in the LFPR of 0.41 percentage points. The increase in those aged 55 to 64 put downward pressure on the LFPR, causing a 0.1 percent decline. As baby boomers begin to approach retirement, however, further downward pressure will be exerted on the overall rate of labor force participation. According to Aaronson et al. (2006), the LFPR will fall by 0.87 percentage points between 2005 and 2010 as a result of the population being more heavily concentrated among older age groups. They expect the increase in the shares aged 55 to 


\section{Figure 5}

\section{LFPR by Age Group}
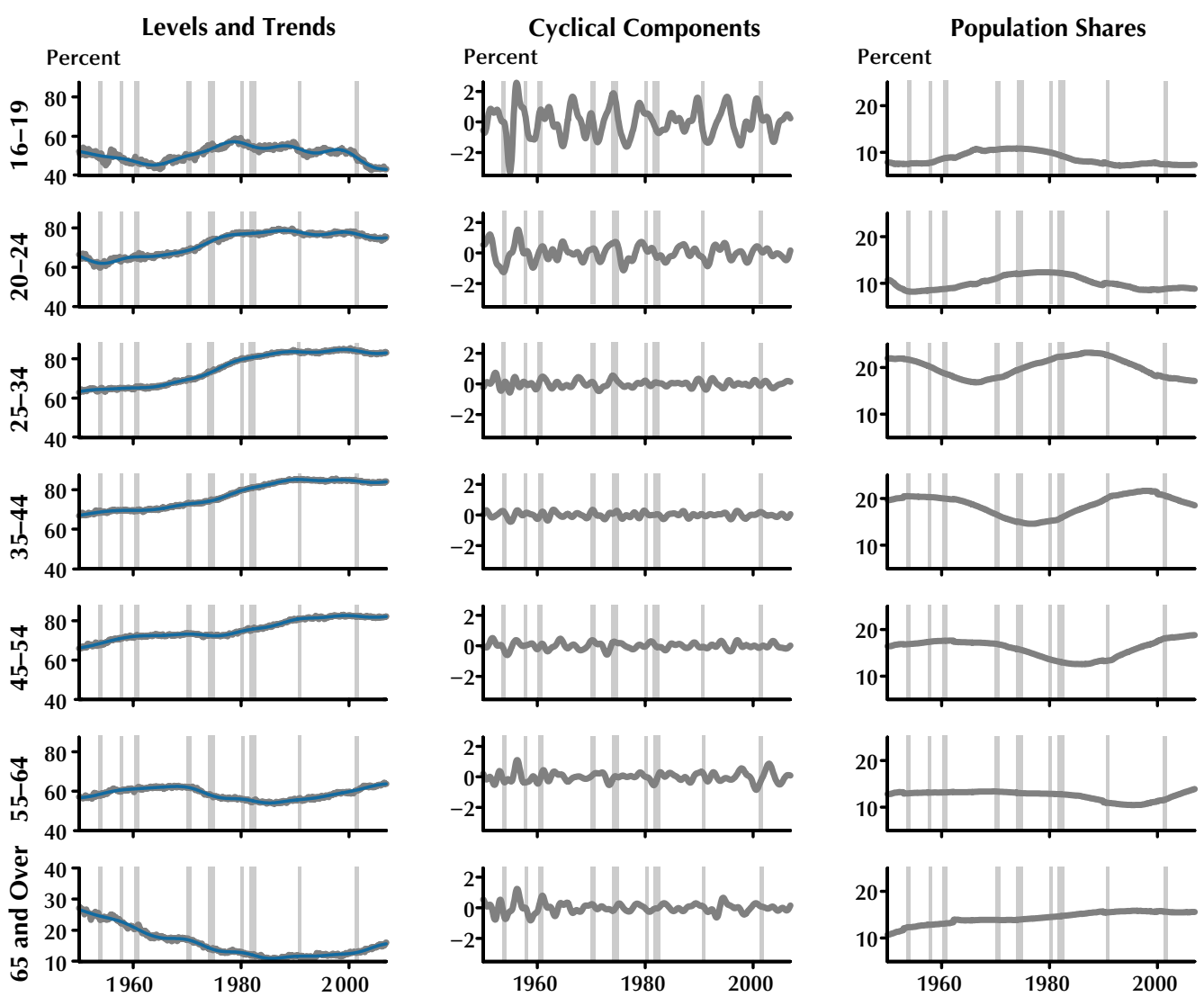

NOTE: Left column: levels (gray) and trends (blue) extracted with an $\mathrm{LP}_{96}$ filter. Middle column: cyclical components extracted with $\mathrm{BP}_{18,96}$ filters. Right column: population shares. The shaded areas denote NBER recessions.

64 and 65 and older to cause a total decline in the LFPR of about half a percentage point.

There is, however, one especially interesting, countervailing trend that has partially offset the natural decrease in the LFPR among an aging population. Within the past two decades, there has been a steady rise in the participation rate among individuals 55 years of age and older (see Figure 5). Just among those aged 55 to 64 , the LFPR has increased by approximately 10 percentage points over the past two decades.

A number of reasons may help explain the increase in participation rates among older workers. ${ }^{11}$ First, the ability to draw full benefits from Social Security depends on a person's year of birth; later generations must work longer to receive full benefits. For example, full retirement occurs at age 65 for individuals born in 1937 or earlier, age 66 for those born between 1943 and 1954, and age 67 for individuals born in 1960 or later. Furthermore, delaying retirement until age 70 allows workers to be eligible for even higher benefits. These features of the Social Security program should push back the age at which some workers exit the labor force (Social Security

${ }^{11}$ Friedberg (2007) gives an overview of some possible explanations for the recent increase in delayed retirement (e.g., changes in Social Security, Medicaid, and Medicare benefits and changes in preferences). 
Table 2

Second Moments of the Business Cycle Components of LFPR by Age Group

\begin{tabular}{lcccccccc} 
& $\mathbf{1 6 - 1 9}$ & $\mathbf{2 0 - 2 4}$ & $\mathbf{2 5 - 3 4}$ & $\mathbf{3 5 - 4 4}$ & $\mathbf{4 5 - 5 4}$ & $\mathbf{5 5 - 6 4}$ & $\mathbf{6 5 +}$ \\
\hline $\operatorname{Cor}(x, i p)$ & 0.55 & 0.30 & 0.18 & 0.10 & 0.03 & -0.14 & 0.10 \\
& $(0.42,0.66)$ & $(0.07,0.50)$ & $(-0.03,0.40)$ & $(-0.11,0.28)$ & $(-0.21,0.28)$ & $(-0.31,0.03)$ & $(-0.07,0.25)$ \\
$\operatorname{Std}(x) / \operatorname{Std}(i p)$ & 0.57 & 0.22 & 0.09 & 0.06 & 0.08 & 0.15 & 0.55 & $(0.45,0.71)$
\end{tabular}

NOTE: ip denotes industrial production. Block-bootstrapped 95 percent confidence intervals are in parentheses.

Administration, 2006). Second, Social Security benefits have grown at a substantially slower pace since the mid-1980s. Data from the Social Security Administration show that real average monthly benefits rose by 88 percent between 1965 and 1985 but by only 23 percent over the following 20 years. For 65 percent of the beneficiaries, Social Security benefits represent over half of their total income (Social Security Administration, 2006). Hence, this decreased growth in benefits could force some retirees back into the labor force to help finance their retirement years. Third, Americans are now living longer than in previous decades. For 65-year-old men, life expectancy has risen by nearly four years since 1970; for women, it has risen by three years. With greater numbers of both productive years in which they can work and "retirement" years that they must finance, individuals may decide to work longer. Fourth, older workers may choose to remain employed longer to maintain health insurance coverage.

Recent surveys (Kaiser Family Foundation and Health Research and Educational Trust, 2006; Kaiser Family Foundation and Hewitt Associates, 2006) have suggested that the fraction of firms offering their active workers the benefit of health insurance after they retire decreased by one-half between 1988 and 2005 (Burtless, 2006). Because workers, in general, do not qualify for Medicare until age 65, this development may also encourage workers to delay retirement.

Along with the baby-boom generations, teenagers have also contributed to the recent decline in labor force participation. Although the teen LFPR has been trending downward since the 1970s, it experienced a sharper-than- usual decline beginning in 2000. Over half of the decline in the overall LFPR since then can be attributed to changes among those aged 16 to 19. Between 2000 and 2003, their LFPR dropped by 7.5 percentage points-a much larger decline than the 0.6-percentage-point drop in the overall LFPR. Since that time, teen participation rates have yet to recover, and they remain around 44 percent (Aaronson, Park, and Sullivan, 2006).

Once again, economists studying this downward trend have identified a number of possible explanations. Because teen workers have a weak attachment to the labor market, they are particularly sensitive to economic downturns. Consequently, when the U.S. economy entered its most recent recession, teen participation rates declined significantly. However, Aaronson, Park, and Sullivan (2006) argue that a weakened demand for teen labor is unlikely to be the main source of the recent downturn, especially because there was no simultaneous increase in the rate at which teenagers reported that they sought employment. Instead, they argue that the failure of the teen LFPR to rebound within the first five years after recovery means that the decline is caused by supply-side factors-namely, the decision to acquire more education.

The fraction of 16- to 19-year-olds who are currently enrolled in school has risen over the past 20 years: from 61 percent in 1987 to 68 percent in 1997, and further to 73 percent by 2005 . A large part of this rise can be linked to the increase in the economic return to education, especially a college degree, since the late 1970s. There is also some evidence that the expansion of educational opportunities, particularly in the 


\section{Figure 6}

\section{LFPR by Race/Ethnicity: Men}

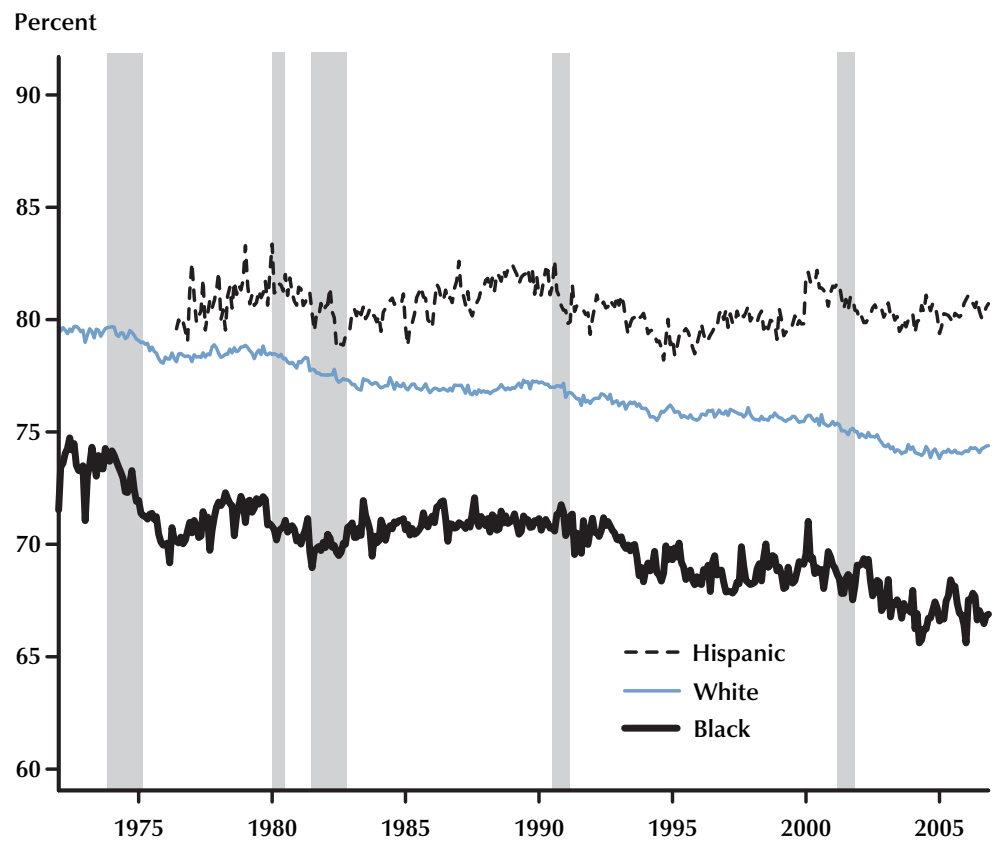

NOTE: The shaded areas denote NBER recessions.

form of increased financial aid, has led to an increase in college enrollment. A possible explanation for the recent larger-than-normal decline in the teen LFPR could stem from teenagers placing even higher value on education than in the past (Aaronson, Park, and Sullivan, 2006).

In addition to its influence on the long-run LFPR trends, the age distribution of the American workforce can also influence the short-run fluctuations exhibited by the aggregate participation rate because there are substantial differences in the cyclical properties of the LFPRs of various age groups. In particular, the business cycle components for persons older than 20 are moderately procyclical/acyclical (Table 2), while teen participation is strongly procyclical. The volatilities are low for those between 25 and 54 years of age, but much higher for young and elderly workers. ${ }^{12}$ Thus, changes in the labor force's age distribution may lead to variations in how the LFPR responds to business cycle conditions.

\section{RACE, ETHNICITY, AND THE LFPR}

A third demographic feature influencing the evolution of the aggregate LFPR is the increase in the racial and ethnic diversity of the U.S. population over the past several decades. Whether because of social, economic, or political factors, participation rates appear to vary across racial groups. Figure 6 plots the LFPRs for white, black, and Hispanic men since the 1970s: Clearly, Hispanic men tend to have higher participation rates than either white men or black men. Over the sample time frames, the average LFPR for Hispanic men was 80.5 percent. White men and black men averaged 76.8 percent and 70.1 percent, respectively. ${ }^{13}$ Similarly, the average yearly

\footnotetext{
${ }^{12}$ The volatilities declined after 1984 by a factor of 1.6 to 1.8 for ages 20 to 54 and by a factor of 1.3 for teenagers. For workers 55 and over, the volatilities increased slightly in the post-1984 period.

${ }^{13}$ The sample spans from January 1972 to November 2006 for whites and blacks and June 1976 to November 2006 for Hispanics.
} 


\section{Figure 7}

\section{LFPR by Race/Ethnicity: Women}

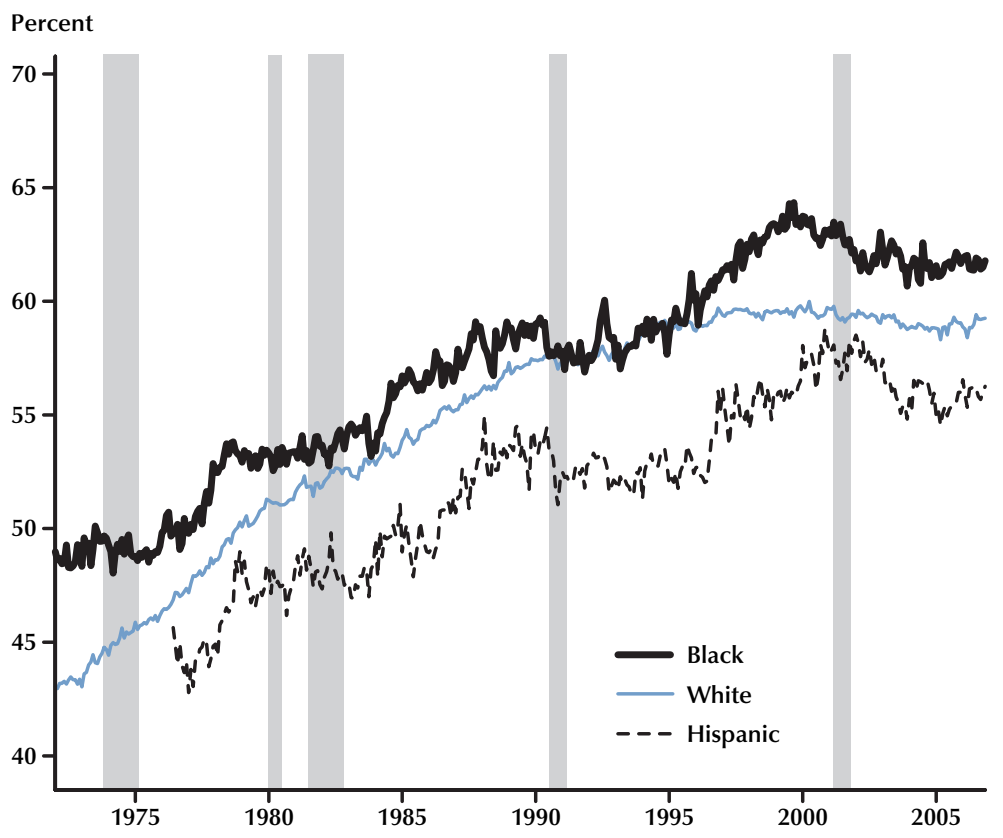

NOTE: The shaded areas denote NBER recessions.

growth rate among Hispanic men was higher than for the other two groups. The LFPR of white men declined by 0.2 percent each year and that of black men declined by 0.3 percent each year on average, while the LFPR of Hispanic men had zero growth on average. From the early 1970s to 2000, the Hispanic share of the total population increased by more than 7 percentage points (to 11.3 percent); it is therefore not surprising that the aggregate U.S. LFPR rose in the decades prior to 2000 .

Among women, however, these three groups show the reverse ordering: Hispanics tend to have the lowest participation rates while blacks tend to have the highest. The average over the entire sample of the LFPR for white, black, and Hispanic women was 54.7 percent, 57.0 percent, and 52.2 percent, respectively. The rise in the fraction of Hispanic women in the population, therefore, very likely had the opposite effect that the rise in the fraction of Hispanic men had: It decreased the average LFPR. Still, participation rates among women of all racial groups showed general increases between 1980 and 2000, and these increases were similar across the three groups (Fullerton and Toossi, 2001). Figure 7 plots the evolution of women's labor force participation broken down by race/ethnicity. In this case, white women experienced the highest average yearly growth in their LFPR. It increased by 0.9 percent each year on average, while Hispanic women saw their LFPR increase by 0.8 percent per year and black women saw theirs increase the least, by 0.7 percent per year.

Once again, a number of explanations exist for differences in rates of labor force participation across races. ${ }^{14}$ One of the most likely causes for the higher LFPR of Hispanic men is that they tend to be younger than the general population

\footnotetext{
${ }^{14}$ For a more complete overview of the black-white gaps in various labor force statistics, see Bradbury (2000).
} 
and in age groups that have higher LFPRs. Several studies cite the increased demand for skilled labor beginning in the 1980s as a reason for some men-especially less-skilled black men-to drop out of the labor force. Chandra (2000) shows that in 1940, employment rates for white and black men were similar across education groups. However, in 1990 the less-educated black men were much less likely to be employed than their white counterparts. Similarly, Bound and Holzer (1993) show that although industrial shifts from manufacturing to other sectors hurt wages for both white and black men, black employment (especially among less-educated young blacks) declined the most during the 1970s, which also carried over into the 1980s.

Although all women saw an increase in their LFPR over this time period, black women saw a much larger increase during the 1990s than the other groups. Juhn and Potter (2006) argue that black women were affected the most by changes in welfare and tax policy during that time, which led to a rise in the LFPR of single mothers.

\section{CONCLUSION: THE FUTURE OF LABOR FORCE PARTICIPATION}

During the past half century, the U.S. LFPR has seen dramatic changes, which have been driven by the rise of women's participation, an aging of the baby-boom generation, and growing ethnic diversity within the general population. What does the future hold for U.S. labor force participation? According to a report published by the Bureau of Labor Statistics, the overall LFPR is projected to decrease slightly to 65.6 percent in 2014 (Toossi, 2005). Two main factors are expected to continue to exert downward pressure on the participation rate: the continued decline in the teen LFPR-which is projected to decline from 43.9 percent in 2004 to 39.3 percent in 2014and the aging of the baby-boom generation. This second factor, however, is likely to lower aggregate participation rates for the next several decades.

As mentioned earlier, the baby boomers have already begun entering into the 55-and-older age category. In her BLS report, Toossi (2005) projected that the fraction of Americans in this age group will rise from 28.4 percent of the adult population today to 33.7 percent by 2014 ; the Census Bureau projects this figure to be 39 percent by 2030. In contrast, the fraction of the population in the prime-age working group is projected to fall from 55.3 percent today to 51.1 percent by 2014 and 47 percent by 2030 .

As baby boomers enter successive age groups, their LFPR should fall dramatically. For instance, the 55 to 59 age group had an LFPR of 72 percent in 2006, and the 60 to 64 age group had an LFPR of approximately 53 percent. Among those 65 and older, the LFPR was just over 15 percent. These numbers, coupled with the increasing proportion of the U.S. population beyond their prime working age over the coming years, suggest that successive generations will be unable to compensate for the baby boomers' exit from the labor force and U.S. labor supply will decline.

To be sure, participation rates for groups 55 and older are expected to increase, which will partially offset the downward pull that older groups have on the overall LFPR. In fact, there is already some evidence of this following the 2001 recession, when this age group had larger-thannormal increases in the LFPR (Bradbury, 2005). In 2014, approximately 41 percent of the group is expected to be in the labor force, up from 38 percent in 2006.

Still, most studies estimate that the rate of labor force growth in the United States will decrease over the next decade, if not longer (e.g., Aaronson et al., 2006). In the event of such a drop-off, it may become increasingly difficult to maintain growth in our standard of living because there will be fewer workers generating goods, services, and income for each resident in the country. The principal challenge in the presence of a declining LFPR, therefore, will be to find ways to enhance the productivity of the individuals that do choose to work. Investing in education, physical capital accumulation, and research and development may be three avenues to such an end. 


\section{REFERENCES}

Aaronson, Daniel; Park, Kyung-Hong and Sullivan, Daniel. "The Decline in Teen Labor Force Participation.” Federal Reserve Bank of Chicago Economic Perspectives, First Quarter 2006, 30(1), pp. 2-18.

Aaronson, Stephanie; Fallick, Bruce; Figura, Andrew; Pingle, Jonathan and Wascher, William. "The Recent Decline in the Labor Force Participation Rate and Its Implications for Potential Labor Supply." Brookings Papers on Economic Activity, 2006, O(1), pp. 69-134.

Baxter, Marianne and King, Robert G. "Measuring Business Cycles: Approximate Band-Pass Filters for Economic Time Series." Review of Economics and Statistics, November 1999, 81(4), pp. 575-93.

Black, Dan; Kolesnikova, Natalia and Taylor, Lowell. "The Labor Supply of Married Women: Why Does It Differ Across U.S. Cities?” Federal Reserve Bank of St. Louis Working Paper 2007-043B, November 2007.

Blau, Francine D. and Kahn, Lawrence M. "Changes in the Labor Supply Behavior of Married Women: 1980-2000." Journal of Labor Economics, July 2007, 25(3), pp. 393-438.

Bound, John and Holzer, Harry J. "Industrial Shifts, Skills Levels, and the Labor Market for White and Black Males." Review of Economics and Statistics, August 1993, 75(3), pp. 387-96.

Bradbury, Katharine L. "Rising Tide in the Labor Market: To What Degree Do Expansions Benefit the Disadvantaged?" Federal Reserve Bank of Boston New England Economic Review, May/June 2000, pp. 3-33.

Bradbury, Katharine. "Additional Slack in the Economy: The Poor Recovery in Labor Force Participation During This Business Cycle.” Public Policy Briefs No. 05-2, Federal Reserve Bank of Boston, July 2005.

Burtless, Gary. "The Recent Decline in the Labor Force Participation Rate and Its Implications for Potential Labor Supply: Comment." Brookings Papers on Economic Activity, 2006, O(1), pp. 135-43.
Chandra, Amitabh. "Labor-Market Dropouts and the Racial Wage Gap: 1940-1990." AEA Papers and Proceedings, May 2000, 90(2), pp. 333-38.

Christiano, Lawrence J. and Fitzgerald, Terry J. "The Band Pass Filter." International Economic Review, May 2003, 44(2), pp. 435-65.

Clark, Todd E. and Nakata, Taisuke. "The Trend Growth Rate of Employment: Past, Present, and Future.” Federal Reserve Bank of Kansas City Economic Review, First Quarter 2006, 91(1), pp. 43-85.

Cohany, Sharon R. and Sok, Emy. "Trends in Labor Force Participation of Married Mothers of Infants." Monthly Labor Review, February 2007, 130(2), pp. 9-16.

Fernández, Raquel; Fogli, Alessandra and Olivetti, Claudia. "Mothers and Sons: Preference Formation and Female Labor Force Dynamics." Quarterly Journal of Economics, November 2004, 119(4), pp. 1249-99.

Fogli, Alessandra; Marcassa, Stefania and Veldkamp, Laura. "The Spatial Diffusion of Female Labor Force Participation: Evidence from US Counties." Unpublished manuscript, New York University, 2007.

Fogli, Alessandra and Veldkamp, Laura. "Nature or Nurture? Learning and Female Labor Force Dynamics." Federal Reserve Bank of Minneapolis, Staff Report 386, February 2007.

Friedberg, Leora. "The Recent Trend Towards Later Retirement." Center for Retirement Research, Work Opportunities for Older Americans, March 2007, 9, pp. 1-7.

Fullerton, Jr., Howard N. and Toossi, Mitra. "Labor Force Projections to 2010: Steady Growth and Changing Composition." Monthly Labor Review, November 2001, 124(11), pp. 21-38.

Goldin, Claudia. "The Quiet Revolution That Transformed Women's Employment, Education, and Family." American Economic Review, May 2006, 96(2), pp. 1-21. 
Goldin, Claudia and Katz, Lawrence F. "The Power of the Pill: Oral Contraceptives and Women's Career and Marriage Decisions." Journal of Political Economy, August 2002, 110(4), pp. 730-70.

Greenwood, Jeremy; Seshadri, Ananth and Yorukoglu, Mehmet. "Engines of Liberation." Review of Economic Studies, January 2005, 72(1), pp. 109-33.

Hotchkiss, Julie L. "Employment Growth and Labor Force Participation: How Many Jobs Are Enough?" Federal Reserve Bank of Atlanta Economic Review, First Quarter 2005, 90(1), pp. 1-13.

Juhn, Chinhui. "Decline of Male Labor Market Participation: The Role of Declining Market Opportunities." Quarterly Journal of Economics, February 1992, 107(1), pp. 79-121.

Juhn, Chinhui and Murphy, Kevin M. "Wage Inequality and Family Labor Supply.” Journal of Labor Economics, January 1997, 15(1), Part 1, pp. 72-97.

Juhn, Chinhui and Potter, Simon. "Changes in Labor Force Participation in the United States." Journal of Economic Perspectives, Summer 2006, 20(3), pp. 27-46.

Kaiser Family Foundation and Health Research and Educational Trust. Employer Health Benefits: 2006 Annual Survey. Publication No. 7527, Kaiser Family Foundation, September 2006.
Kaiser Family Foundation and Hewitt Associates. Retiree Health Benefits Examined. Publication No. 7587, Kaiser Family Foundation, December 2006.

Social Security Administration. Annual Statistical Supplement to the Social Security Bulletin, 2005. SSA Publication No. 13-11700, February 2006.

Stock, James H. and Watson, Mark W. "Has the Business Cycle Changed and Why?” in Mark Gertler and Kenneth Rogoff, eds., NBER Macroeconomics Annual 2002. Boston, MA: MIT Press, 2003.

Toossi, Mitra. "A Century of Change: The U.S. Labor Force, 1950-2050." Monthly Labor Review, May 2002, 125(5), pp. 15-28.

Toossi, Mitra. "Labor Force Projections to 2014: Retiring Boomers." Monthly Labor Review, November 2005, 128(11), pp. 25-44.

Toossi, Mitra. "A New Look at Long-Term Labor Force Projections to 2050." Monthly Labor Review, November 2006, 129(11), pp. 19-39.

Welch, Finis. "Wages and Participation." Journal of Labor Economics, January 1997, 15(1), Part 2, pp. S77-S103. 


\section{APPENDIX}

\section{Trend and Business Cycle Components}

Any time series can be decomposed into cyclical components of different frequencies. The frequency of a cycle is inversely related to its period. The period of a cycle is simply the time between subsequent peaks. We consider three components:

Trend component: The trend is obtained by removing fluctuations with periods higher than 8 years (i.e., 96 months) with a low-pass filter.

Business cycle component ${ }^{15}$ : We extract the business cycle component of a time series using a bandpass filter, which removes the trend component (period higher than 8 years) and the high-frequency component (period less than 1.5 years).

High-frequency component: This corresponds to fluctuations with periods less than 1.5 years.

Figure A1 illustrates this decomposition for industrial production. We use the business cycle component of industrial production to determine the correlation of participation rates for various demographic groups with aggregate economic activity over the business cycle (see Tables 1 and 2).

\section{Figure A1}

\section{Industrial Production}
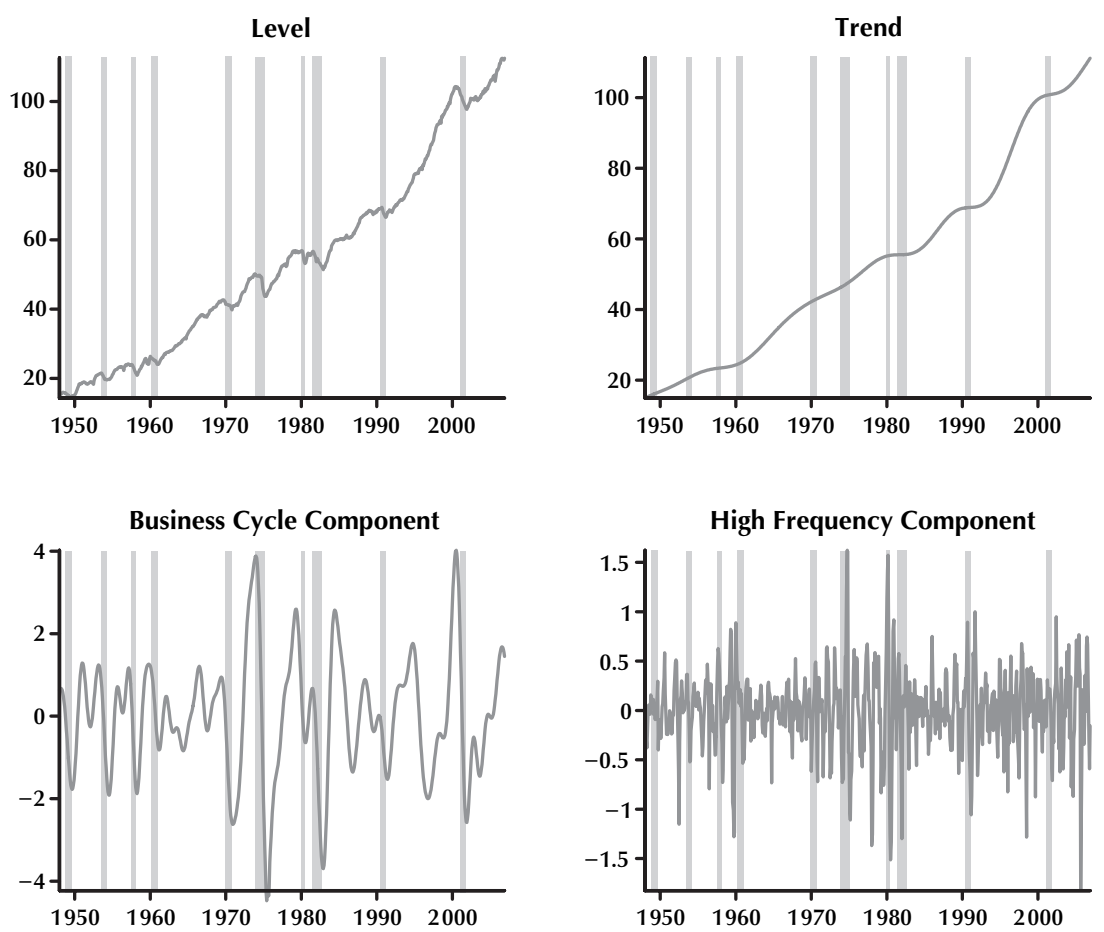

NOTE: Industrial production data are from the Federal Reserve Board. The shaded areas denote NBER recessions.

\footnotetext{
${ }^{15}$ We sometimes refer to the business cycle component as the cyclical component with a slight abuse of terminology.
} 